\title{
Inclusion of a somatic approach in post-conflict societies as a component for increased inclination to peacebuilding and reconciliation: preliminary evidence from the field
}

\author{
Rok Zupančič ${ }^{1}$ \\ University of Ljubljana
}

\author{
Laurie Leitch ${ }^{2}$ \\ Threshold GlobalWorks
}

\begin{abstract}
Contemporary neuroscience research has shed important light on the way the mindbody system responds to threat and fear. As a result, somatic approaches that build on neuroscience research are now gaining visibility as they offer practical ways for individuals and communities to self-regulate following traumatic events. Somatic approach (intervention) focuses on sensory/physiological experience and only secondarily on emotion and cognition. In this study, we present preliminary data from field work based on somatic approaches in societies affected by large-scale natural disasters and in Rwanda post-genocide. We then make the case for the inclusion of somatic approaches (as an intervention) in both the theory and practice of peacebuilding. The results have demonstrated that using somatic approaches - also called mind-body, or integrative approaches -, in which an individual's attention is directed to sensory experience as a way to access and regulate the human nervous system, are beneficial for reducing the cascade of physical, emotional, cognitive, behavioural, and spiritual responses to stressful, distressing and traumatic events. Learning the capacity to self-regulate, thereby reducing anger, fear, stress and other 'negative physiological responses' present in post-conflict societies, by the use of somatic intervention could yield positive results for amplifying the pro-social behaviours of the citizenry. In the longer run, this could perhaps also lead to an increased orientation of people living in post-conflict societies to support and engage in peacebuilding and reconciliation.
\end{abstract}

\section{Introduction}

In the countries that have experienced war, ethnic violence, and other forms of extended violence the first order of peacebuilding approaches is often to examine the larger system factors (governance, ethnic factions, legal structures, media, etc.) that are considered causal factors in rebuilding stability. Interventions are then targeted at these domains. It could be, thus, argued that the current paradigm of (liberal) approach to peacebuilding in post-conflict societies, often a sort of 'mission civilisatrice' (Paris, 2002) or, at least, underpinned by a specific ideology (Rambsotham, 2000) rests on a few assumptions. Namely, that the building of a peaceful society - and eventual reconciliation - is possible if:

a) political power-sharing in a newly-developed society is secured (Jung, 2012);

\footnotetext{
${ }^{1}$ Rok Zupančič, PhD, is Associate Professor at University of Ljubljana, Faculty of Social Sciences. Correspondence: rok.zupancic@fdv.uni-lj.si

${ }^{2}$ Laurie Leitch, PhD, is Director of Threshold GlobalWorks, New York, U.S.A.
} 
b) rights of all people in a society, including minorities, are respected (Klatt, 2017);

c) economic opportunities for all people are secured (Pugh, 2005),

d) state institutions are impartial and start operating in a professional manner (Shinoda, 2018),

e) better mutual understanding is achieved - if not even empathy - among the people that have been previously fighting each other (Head, 2016).

However, studies in peacebuilding have shown that several combinations of these peace-building strategies and instruments - and huge financial investments in them by the UN, the EU and other donors - do not necessarily lead to the decrease of tensions among the people previously involved in armed conflict, let alone reconciliation (Doyle and Sambanis, 2000). Thus, the overarching question for peacebuilders remains the same: what combination of peace-building strategies and instruments should be introduced and implemented in a post-conflict society so that the people belonging to the two (or more) groups previously involved in violent conflict would start perceiving each other in a less adversarial way and would, eventually, start jointly working for a common good and reconciliation of a war-torn society?

To this day, we still do not know why so many peace-building efforts are not successful or even completely fail. Not only does this fundamental question for peacebuilding scholars and practitioners not have a clear-cut answer; on the contrary, the post-conflict phase often brings fragile peace only - the unstable 'peace'. This instability is most likely due to several unresolved issues at the level of societies as well as at the individual level, including the relations between groups. The instability may be reflected in the continuation of war (Mlambo, 2008), with perhaps slightly less violent means, and can easily turn back to a full-fledged violence.

In fact, the most-often neglected element in the discussions of how to 'do' peacebuilding are the individuals - and their psychosocial well-being or lack of it. Every system, and post-conflict societies are not an exception, is made up of individuals, individuals who often have been functioning from a base of threat, fear, anger, and disillusionment. It does have to be acknowledged that the call for the inclusion of emotions into the analysis of peacebuilding is not new (e.g., Bramsen and Poder, 2018). Despite this, the interventions by the international community that have been designed for individuals in post-conflict societies are often cognitive models, which can be helpful but may not be culturally sensitive in non-insight oriented populations or in traumatized populations and are often unable to provide practical skills that can be used in an on-going way by individuals for self-regulation. In the past decade exciting models of intervention have been developed that are based in neuroscience research (see, for example Hameiri, BarTal \& Halperin, 2019; McDonald et al, 2019; Leitch, 2009, 2010). 
Due to advances in neuroimaging techniques and interpretation, contemporary neuroscience has much to offer the peacebuilding arena. For example, neuroscience research has found that when individuals, both children and adults, live in unstable, unpredictable, and frightening situations there is often a long-term impact on the human nervous system (van der Kolk, 2014). In addition to the cascade of physical and psychological health issues that are well documented, living with the effects of violence is also associated with a decrease in pro-social, cooperative behaviours and increases in family and cross-group violence (Scaer, 2015; Staub, 2015). As Staub (2015: 190) points out, the frustration of individuals' basic needs such as security, trust, positive connections to other people, and positive identity by their social conditions is one cause of groups turning against other groups. These dynamics, as neuroscience research points out, can "re-wire" the brain for increased reactivity, and must be attended to if restoration of peace and stability is to be long-lasting and human potential and resilience is to be maximized.

A relevant example where above-mentioned challenges are present, are post-conflict societies. In this short pre-study we are making the case for the inclusion of somatic approaches in peacebuilding, by which we expect to reduce the chronicity of anger, fear, stress and other 'negative emotions' generated by war that have become embedded in the mind-body system. Incorporating somatic components into comprehensive peacebuilding strategies can enhance pro-social behaviours as well as an array of health indicators of people living in post-conflict societies. This could, in the longer run, contribute to a greater acceptance of and participation in peacebuilding strategies applied by the international community, and could contribute to an increased readiness and willingness for reconciliation.

\section{Intervention methodology}

As Functional Magnetic Resonance brain scan technology (fMRI) has been refined, neuroscience research has increasingly come to the attention of those individuals and groups working with today's most challenging social problems, particularly those that include conflict and violence. The Social Resilience Model (SRM), ${ }^{3}$ which is one of the somatic approaches, is draws upon neuroscience research about how human beings are neurologically wired to respond to threat and fear, what is needed in order to build resilient citizens and communities, and how the capacity for resilience is built into each person in a way that is accessible by targeted intervention. Neuroscience research has also highlighted the plasticity of the brain, meaning that the brain changes itself based on experience. When individuals are equipped with and practice skills for self-regulation they can change the brain's reactivity and decrease the power of stressors on the mindbody system. SRM training, as well as other somatic approaches, is suitable across

\footnotetext{
${ }^{3}$ Earlier versions of this model have been called Trauma First Aid (TFA) and Trauma Resilience Model (TRM).
} 
diverse groups and cultures and with populations not oriented toward insight-based, cognitive interventions. Cognitive approaches are also of limited benefit as a first stage intervention when individuals are highly, and chronically dysregulated due to a history of de-stabilizing events. In these cases the stress chemicals block cognitive functioning.

SRM is a practical, skills-based intervention designed to 1) teach self-regulation skills, 2) stabilize and 3) through practice, rewire the nervous system for greater resilience. The model is based upon extensive research that has emerged from the neuroscience field called "Attention Science" in which, using self-directed attention, the brain's capacity to re-wire itself for greater hardiness and resilience (neuroplasticity) can be accessed and reinforced. Use of SRM's practical skills can reduce and/or mediate the cascade of physical, emotional, cognitive, behavioural, and spiritual responses to stressful, distressing, and traumatic events that can last for many years. SRM's early projects were in natural disaster settings around the world. Currently, SRM is being used in Rwanda in prisons housing perpetrators of the genocide against Tutsis (Barnes-Ceeney, Gideon, Leitch, Yasuhara, 2019).

Somatic approaches, in which attention is directed to sensory experience as a way to access and regulate the human nervous system, are beneficial for reducing the cascade of physical, emotional, cognitive, behavioural, and spiritual responses to stressful, distressing and traumatic events. SRM, as one of these approaches, emphasizes the primacy of sensory experience and secondarily focuses on emotion and cognition. This is because once regulation occurs at the sensory level (i.e., nervous system) thoughts and emotions come into balance. Reducing anger, fear, and other 'negative emotions', all omnipresent in post-conflict societies, could yield positive results for a more resilient citizenry, including utilization of pro-social behaviours and improved health SRM, as we argue in this paper, could be a beneficial component to contribute successful peacebuilding.

\section{Evidence from limited samples}

In an exploratory study of fifty-three survivors of the Thailand tsunami in 2004 two to three SRM sessions of 45 minutes each were provided one month after the tsunami. Survivor assessments were done pre-treatment, immediately post-treatment, three to five days post-treatment, and at the one-year follow-up. Results indicated that, immediately following treatment, $67 \%$ of participants had partial to complete improvement on reported symptoms and $95 \%$ had complete or partial improvement on observed symptoms. At the one year follow-up $(n=22) 90 \%$ of participants had complete or partial improvement in reported symptoms and $96 \%$ had complete or partial improvement on initially observed symptoms. At the one-year follow-up, an untreated public health sample was used for comparison. 
Another SRM disaster study (Leitch, Vanslyke, Allen, 2009) was implemented from 20052007 with a purposeful sample of 142 caregivers and first responders who were survivors of Hurricanes Katrina/Rita in the United States. Ninety-one participants received 2-3 SRM sessions and were compared with a statistically-matched comparison group of 51 using Propensity Score Matching. All participants first received group psychoeducation. Results support the benefits of SRM with the treatment group showing statistically significant gains in resiliency indicators and decreases in PTSD symptoms.

In addition to above-mentioned natural disaster projects (in China, Haiti, Nepal) SRM has been used after human-caused disasters as well. Beginning in 2008 SRM was used to train mental health providers in Kenya after the post-election violence and in Rwanda with genocide survivors. In Rwanda, the workers themselves were also survivors of the 1994 Genocide against Tutsis (as it is now called). SRM skills are used for self-care as well as care of others and the counsellors were taught to use the skills in both ways.

Another example of the potential of somatic approaches has been recently applied in Israel; the exploratory study demonstrated, though on a relatively small number of participants $(n=63)$, that the use of Somatic Experiencing, which is one of the bodyfocused therapies, has a positive effect in treating people with posttraumatic stress disorder (PTSD) (Brom, 2017). Somatic Experiencing is a clinical model, requiring trained therapists to deliver it. This may limit its accessibility in populations who either will not (due to fear or stigma) or cannot (due to expense, or geographic accessibility) go to a therapist. The SRM is a model that non-clinicians can use. In fact, a core component of SRM is its Train the Trainer component in which local people are trained to teach the skills in their own communities.

\section{Making the case for inclusion of somatic approaches in peacebuilding and proposing a new comparative research venue}

The findings, in spite of the small sample sizes mentioned above, suggest that integrative, mind-body interventions based on neuroscience such as SRM have promise. We believe that somatic approaches can be utilized also in peacebuilding, in which selfreported or observed physical and emotional symptoms of self-dysregulation are present, and pro-social attitudes and/or behaviours are lacking towards the outgroup(s). In this section, we present a case example that supports our main argument for the necessity of including somatic interventions as components of the peacebuilding approaches of international and the local communities.

The argument draws upon preliminary evidence from the Rwanda PeaceBuilder Project, which has been on-going during the writing phase of this paper (2019). The PeaceBuilder Model seeks to build strength and resilience among genocide-impacted individuals and communities that are characterized by fractured relationships that 
impede social and economic well-being and safety as well as an array of negative health indicators. The project built partnerships with key Peace and Reconciliation groups in Rwanda and individuals from these groups participated in helping to design the structure of the project as well as participating in meetings about the translation of survey and interview protocols, cultural and historical dimensions that had to be considered, and connections to local and government officials. Meetings were held with key members of the various systems that have authority in the country. This has helped insure a climate of trust and collaboration.

In its first phase local individuals were trained in data collection (survey implementation and interviewing). Baseline data was collected from genocide perpetrators in 3 Rwandan prisons $(n=302)$ prior to the SRM and Council/Listening Circles which constitutes the intervention. Data collected at baseline in 2016 found that two thirds of the incarcerated 'genocidaires' - persons convicted of committing the genocide - had high levels of posttraumatic stress symptoms, anxiety, depression as well as diagnosable PTSD, and an array of physical health problems 22 years post-genocide (Barnes-Ceeney, Gideaon, Leitch, Yasuhara, 2019). This highlights the long-lasting impact of violent events and why it can be so difficult to build a stable peace in countries where there has been widespread trauma.

The 'genocidaires' selected to participate in the project were those scheduled to be released back to their communities in 2-3 years. This timeframe allowed them to use the skills for self-care and peer-to-peer (with support from project staff) as well as to develop confidence by having a set of skills to offer when they are released back to their communities. Learning to self-regulate using SRM skills can help decrease physical and emotional symptoms as well as strengthen pro-social behaviours before re-entry into their communities. The ability to use SRM peer-to-peer is an important benefit in a country in which there is very little access to professional care. Research at baseline in 2016 found that two thirds of the incarcerated 'genocidaires' had high levels of posttraumatic stress symptoms, anxiety, depression as well as diagnosable PTSD 20 years post-genocide. This highlights the long-lasting impact of violent events. As the baseline data shows, individuals who commit atrocities also suffer from traumatic symptoms, which, when unattended, can impede the capacity for reunification and reconciliation.

Phase 2 of the PeaceBuilder Project is designed to train 'genocidaires' as well as community survivor groups as trainers in SRM to enhance pro-social behaviours, improve health indicators, and build collaboration across difference. The Train the Trainer program (a core dimension of SRM training) will build scalability and sustainability across the country. It will also provide both perpetrators and providers with a shared understanding of the impact of violence, the symptoms that results, and ways to mediate the symptoms. The utilization of training pairs in which one trainer is a 
genocidaire and the other is a survivor is also intended to foster collaboration and prosocial behaviours.

For comparative reasons and verification of our argument, we propose to conduct the following study, which would follow two lines of research. First, the seminars relying on the usual approaches for lessening the distrust, prejudice and social distance will be organized in a given post-conflict society (what we call 'the usual suspects in peacebuilding', e. g. story-telling projects between the groups in conflict, joint-history projects, seminars and workshops, in which people from all parties in conflict participate and 'learn from each other' and other similar efforts that receive vast financial and political support within the existing, liberal paradigm of peacebuilding). These seminars would be organized in coordination with international donors, who have been supporting such peacebuilding efforts for decades. The measurement of people's inclination to peacebuilding and reconciliation would be done before and after the seminar to see, whether the 'usual suspects in peacebuilding' have contributed to the change of attitudes.

Soon after this 'cognitive-based seminar' is completed, the second seminar building on the somatic approach, Social Resilience Model (SRM) would be organized with approximately half of the people participating at the first seminar. Using the survey, the attitudes toward peacebuilding and reconciliation would again be measured before and after this second, somatically-oriented seminar. Finally, the results between the control (first group) and experimental (second) group will be compared. This will allow us to tell the degree to which the trauma-informed, neuroscience-based (somatic) techniques, which take into consideration the perspectives fairly neglected in the existing peacebuilding paradigm (nervous system and other biological/physiological aspects of human beings), can successfully complement the existing approaches in peacebuilding and add a thus far missing component to stable peace in post-conflict societies.

We recognize that peacebuilding is a complex and multi-faceted endeavour, requiring a systems orientation. Although the evidence has shown that the use of somatic approaches can contribute to peace by amplifying the use of pro-social behaviors and emotional self-regulation, these "individual achievements" have yet to be incorporated in a wider sustainable system of post-conflict society. This project addresses this "missing link" in the design of peacebuilding planning. If at the larger societal level of the postconflict society there is no coordinated effort to unify people, any work at the individual level cannot be as effective and vice versa. Thus, it is necessary to bring a handful of large systems' variables into a multivariate analysis (economic opportunities, distribution of wealth, poverty, fairness of political system and access to power, functional educational system, respect for human rights etc.) and explore their possible mediation (interference) in the eventual change of peoples' attitudes toward peacebuilding and reconciliation; for example, using the attitudes to inclination/peacebuilding as the 
dependent variable and key large systems' variables and SRM scores as independent variables.

\section{Conclusion}

In this short pre-study, by which we aimed to make the case for the inclusion of somatic approaches to amplify the effectiveness of existing peacebuilding processes. We believe that a systems-oriented combination of structural factors is of an utmost importance for any kind of positive change coming from the peacebuilding/reconciliation projects international and local. At this stage of development in our work, we do not plan to measure neither the level of reconciliation nor the success of peacebuilding (both hardly contested concepts). Rather, we seek to explore the extent to which the inclination of people to be active participants in peacebuilding/reconciliation after the application of somatic approaches increases.

In future research, therefore, the next step would be to supplement 'the existing peacebuilding paradigm' - which primarily strives at improving structural factors (better political system, improved functioning of other state institutions, respect for human rights etc.) and builds mostly on cognitive-only approaches (seminars, where people from all sides learn of the suffering of 'the other'; common history projects; learning about wrong-doings on both sides etc.) - with somatic approaches. Namely, we believe that individuals' self-regulation is a pre-condition for a 'successful landing' of any kind of top-down or middle-out (peacebuilding) approaches on human beings. Unstable and dysregulated individuals, whose nervous systems are stuck in the reactivity generated by chronic exposure to threat and fear, and, for many, with continuing experiences of "small-scale wrong-doings" or even traumatic experiences from armed conflict and later in a post-conflict phase, are not able to accurately experience post-conflict reality and "absorb" the efforts of internationally- or local-led peacebuilding initiatives. This missing link deserves to be addressed.

\section{References}

Barnes-Ceeney, K., Gideon, L., Leitch, L., Yasuhara, K. 2019. Recovery After Genocide: Understanding the Dimensions of Recovery Capital Among Incarcerated Genocide Perpetrators in Rwanda. Frontiers in Psychology, vol. 10. April 2019. Retrieved from: https://doi.org/10.3389/fpsyg.2019.00637

Bramsen, I., Poder, P. 2018. Emotional Dynamics in Conflict and Conflict Transformation. Berghof Handbook for Conflict Transformation, Online Edition. Berlin: Berghof Foundation. Retrieved from: https://www.berghoffoundation.org/fileadmin/redaktion/Publications/Handbook/Articles/bramsen_poder_hand book.pdf (25 June 2019).

Brom, D., Stokar, Y., Lawy, C., Nuriel-Porat, V., Ziv, Y., Lerner, K., Ross, G. 2017. Somatic Experiencing for Posttraumatic Stress Disorder: A Randomized Controlled Outcome Study. Journal of Traumatic Stress 30(3): 304-312. 
Doyle, M. and Sambanis, N. 2000. International Peacebuilding: A Theoretical and Quantitative Analysis. American Political Science Review 94 (4): 779-801.

Hameiri, B., Bar-Tal, D., Halperin, E. 2019. Paradoxical thinking interventions: a paradigm for societal change. Social Issues and Policy Review 13(1): 36-62.

Head, N. 2016. A politics of empathy: encounters with empathy in Israel and Palestine. Review of International Studies 42(1): 95-113.

Jung, J. 2012. Power-sharing and democracy promotion in post-civil war peace-building. Democratization 19 (2012). Retreived from: https://www.tandfonline.com/doi/abs/10.1080/13510347.2012.674359

Klatt, M. 2017. Minorities as secondary foreign policy agents in peace-building and reconciliation? The case of Denmark and Germany. Regional and Federal Studies 27 (3): 239-259.

Leitch, L., Vanslyke, J., Allen, M. 2009. Somatic Experiencing Treatement with Social Service Workers Following Hurricanes Katrina and Rita. Social Work 54 (1):9-18.

Leitch, L. 2010. Information Gathering After Trauma: Considerations for Human Rights Workers, Peace Building and Interviewing. Africa Peace and Conflict Journal 3 (1) June 2010: 80-87.

McDonald, M., Brindley, S., Halperin, E., Saguy, T. 2019. Promoting intergroup openness and support for equality in a new cultural context: replicating the effects of internal criticism. The Journal of Social Psychology 159(3): 349-356.

Mlambo, N. 2008. Violent conflicts, fragile peace: perspectives on Africa's security problems. London: Adonis \& Abbey Publishers.

Paris, R. 2002. International peacebuilding and the 'mission civilisatrice'. Review of International Studies 28: 637-656.

Pugh, M. 2005. The political economy of peacebuilding: a critical theory perspective. International Journal of Peace Studies 10(2): 23-42.

Ramsbotham, O. 2000. Reflections on UN Post-Settlement Peacebuilding. International Peacekeeping 7 (1): 169-89.

Scaer, R. 2015. The Trauma Spectrum: Hidden Wounds and Human Resiliency. New York: W.W. Norton and Company.

Shinoda, H. 2018. Peace-building and State-building from the Perspective of the Historical Development of International Society. International Relations of the Asia-Pacific 18 (2018): 25-43.

Staud, E. 2015. The Roots of Goodness \& Resistance to Evil. Oxford: Oxford University Press.

Van der Kolk, B. 2014. The Body Keeps the Score. New York: Penguin Books. 